This item was submitted to Loughborough's Research Repository by the author.

Items in Figshare are protected by copyright, with all rights reserved, unless otherwise indicated.

\title{
Information discernment and the psychophysiological effects of misinformation
}

PLEASE CITE THE PUBLISHED VERSION

https://doi.org/10.1108/GKMC-03-2021-0052

PUBLISHER

Emerald

VERSION

AM (Accepted Manuscript)

\section{PUBLISHER STATEMENT}

This paper was accepted for publication in the journal Global Knowledge, Memory and Communication and the definitive published version is available at https://doi.org/10.1108/GKMC-03-2021-0052

\section{LICENCE}

CC BY-NC 4.0

\section{REPOSITORY RECORD}

Walton, Geoff, Matt Pointon, Jamie Barker, Martin Turner, and Andrew Wilkinson. 2021. "Information Discernment and the Psychophysiological Effects of Misinformation". Loughborough University. https://hdl.handle.net/2134/15091323.v1. 


\section{Global Knowledge, Memory and Communi}

\section{Information discernment and the psychophysiological effects of misinformation}

\begin{tabular}{|r|l|}
\hline Journal: & Global Knowledge, Memory and Communication \\
\hline Manuscript ID & GKMC-03-2021-0052.R1 \\
\hline Manuscript Type: & Article \\
\hline Keywords: & $\begin{array}{l}\text { Information literacy, information discernment, information behaviour, } \\
\text { psychology, Cognition, psychophysiology, PANAS, stigmatization, } \\
\text { affective state, Metaliteracy }\end{array}$ \\
\hline
\end{tabular}

\section{SCHOLARONE Manuscripts}




\title{
Information discernment and the psychophysiological effects of misinformation
}

\begin{abstract}
Purpose: To determine to what extent a person's psychophysiological well-being is affected by misinformation and whether their level of information discernment has any positive or negative effect on the outcome.
\end{abstract}

Design/methodology/approach: Participants $(\mathrm{n}=48)$ were randomly and blindly allocated to one of two groups: (1) Control Group participants were told a person they were working with was a student. (2) Experimental Group participants were additionally led to believe that this other participant had extreme religious views. This was both stigmatising and misinforming as this other person was an actor. Participants completed a pre-screening booklet and a series of tasks. Participants' cardiovascular responses were measured during the procedure.

Findings: Participants with high levels of information discernment ie those who: are curious, use multiple sources to verify information, are sceptical about search engine information, are cognisant of the importance of authority and are aware that knowledge changes and is contradictory at times exhibited an adaptive stress response i.e., healthy psychophysiological outcomes and responded with positive emotions before and after a stressful task.

Originality: The first study to combine the hitherto unrelated theoretical areas of information discernment (a sub-set of information literacy), affective states (PANAS) and stress (challenge and threat cardiovascular measures).

Social implications: The findings indicate the potential harmful effects of misinformation and discuss how information literacy or Metaliteracy interventions may address this issue.

Keywords: Information literacy, information discernment, information behaviour, psychology, cognition, psychophysiology, PANAS, stigmatization, affective state, Metaliteracy

Classification: Research paper

\section{Introduction}

Information that is incorrect and circulated accidently or to deliberately mislead for whatever reason has become a global problem brought into sharp relief by the pandemic (Spring, 2020a). One specific example being the 'Infodemic' (Zaracostas, 2020). It has many names such as, misinformation, disinformation, fake news, post-truth and alternative facts. For this article the term misinformation is preferred as the umbrella label for this range of false information related concepts. Misinformation is mentioned in common parlance as if it were an entirely new phenomenon, possibly because according to Freelon and Wells (2020) 'fake news' as a term was first coined in 2016. However, the problem of misinformation is a long and recurrent theme in history (Freedland, 2017; Piccolo et al., 2019). The fictitious work 'The Jewish peril: the protocols of the learned elders of Zion' (Nilus, 1905) and its use by the German Nazis to 'prove' a global conspiracy (Bytwerk, 2015) demonstrate that 'fake news' is nothing new. What is new however is the shear amount of misinformation circulating and the velocity at which it travels through the digital sphere (Vosoughi et al., 2018).

This article examines the misinformation phenomenon, discusses how ideas in information literacy and newer, closely related areas such as Metaliteracy and information discernment are positioned to address this issue. The literature review concludes that there is a knowledge gap in the understanding of the underlying physiological processes relating to stress responses accompanying the psychological, social, behavioural and information source processes in information discernment. By exploring these phenomena it is argued that people exhibit either high or low levels of information discernment and that these levels will have a bearing on their physiological response. By addressing this knowledge gap a more comprehensive understanding of what is involved both psychologically and physiologically in the process of making judgements about information may be achieved. 
To explore the relationship between levels of information discernment and physiological processes more fully the following hypothesis is suggested:

H1:Those who score highly in the information discernment questionnaire (IDQ) report significant differences in the ways that they respond to questions about confirmation bias, epistemic beliefs, motivated reasoning and how they evaluate information to those with low levels of information discernment.

$\mathrm{H} 2$ : When participants encounter misinformation, those who report high levels of information discernment will exhibit a challenge state (positive stress response) and positive emotional and cardiovascular responses. Conversely, those who report low levels of information discernment will experience a threat state (negative stress response) and a negative emotional and cardiovascular responses.

\title{
Misinformation, disinformation and related phenomena
}

There is a rich literature on the topic of misinformation. This discussion draws upon the growing number of meta-analyses, reports and papers which discuss the main issues in this field.

\begin{abstract}
Before misinformation itself is considered, it is necessary to clearly articulate what is meant by 'information'. The notion inspired by Bateson (1972 in Case and Given, 2016, p.56) is preferred stating that information is 'any difference which makes a difference to a conscious, human mind' and qualified with 'a difference which makes a difference is an idea. It is a "bit," a unit of information' (Bateson, 1972, p.276). Information then can be in any form, auditory, textual, visual or digital. This characterises information in the broadest sense and is a useful foundational definition for this research.
\end{abstract}

Defining or even naming the phenomenon that is false information is in-itself an issue and there are many attempts at doing so (for example, Edwards et al., 2021; Freelon and Wells, 2020; Rubin, 2019). Lewandowsky and Yesilada (2021) offer a way forward. 'Fake news' and 'alternative facts' can be regarded as forms of misinformation, defined as 'information that is either false or inaccurate' (Lewandowsky and Yesilada, 2021, p.7). For the term disinformation, a slightly different definition of is proffered, 'when misinformation is spread intentionally, for example in pursuit of a political agenda, we refer to it as disinformation' (Lewandowsky and Yesilada, 2021, p.7). For the literature review and discussion the term misinformation will be used as a generic term to describe any false information. For the experiment described later, because participants were exposed to deliberately constructed false information, the second more granular term disinformation and its definition applies.

Misinformation is becoming ever more pervasive and problematic and the subjects identified are wide ranging for example, climate change, vaccination misinformation, GM crops, political misinformation (Edwards et al., 2021). Misinformation is the focus of a large EU funded project Provenance (Kennedy, 2018), with some regarding fake news as having 'the potential to undermine democracy' (Jane Suiter quoted in Morgan, 2018, n.p.). For political misinformation and its associated conspiracy theories witness the unprecedented events on Capitol Hill fuelled by outgoing President Trump's insistence that the Presidential Election had been 'stolen' (Kahn et al., 2021). 'Stop the steal' has become a powerful slogan for those who believe in this conspiracy theory (Spring, 2020b). Various initiatives in the UK and EU have been set in train to address other aspects of misinformation. A strategy has now been produced by the Department for Digital, Culture, Media and Sport which recognises that 'information literacy supports users' critical thinking skills and understanding of the journalistic process' (DDCMS, 2021, p.7).

Meta-analyses of conspiracy theories (Douglas et al, 2019) and extremism misinformation (Emmelkamp et al., 2020) foreground contextual (social), psychological, affective, epistemic and behavioural states as important factors in extremism and conspiracy theory ideation. Peoples' tendency to have a default position of trust when making judgements about information also has a bearing on how misinformation is consumed. This was confirmed in work on the Measles Mumps and Rubella (MMR) vaccination scandal (Lewandowsky et al., 2012). People trusted news articles linking MMR to autism by default and consequently vaccine rates diminished and measles infections 
increased (Lewandowsky et al., 2012). This was further corroborated by Walton et al (2018) in their work with 16-17 year-olds who found participants exhibit this default position stating that they tend to trust their parents without question.

Inoculation theory has come to prominence as a possible solution which enables people to make wellcalibrated judgements about information (Cook et al., 2017). However, Hicks (2021) argues that this inoculation metaphor characterises individuals as passive and vulnerable rather than being able to actively resist or contest messages. This chimes with other researchers who voice concerns that previous research into these specific forms of misinformation associated with conspiracy theory and extremism ideation in particular have not investigated people's ability to actively process information in order to promote analytical thinking (Douglas et al, 2019) such as making credibility judgements about websites (Keshavarz, 2020). Whitworth (2020a, p.25) regards information literacy as a potential solution, being in-itself a political act, 'enmeshed in formal and informal decision-making'. These are promising observations for the role of information literacy. In support of this argument Lewandowsky et al $(2017$, p.363) in their meta-analysis note that 'general training in information literacy is required so students learn which information to trust, particularly online. Recent efforts have yielded promising results (e.g., Walton \& Hepworth, 2011)'. Additionally, Mackey and Jacobson, 2011; Jacobson and Mackey, 2013; Jacobson et al., 2018; Mackey, 2020) identify analytical thinking, affect and behavioural factors in their Metaliteracy model (discussed below) which could provide a framework for enabling students in higher education to combat harmful misinformation. This carves out a role for information literacy in providing part of the solution to these societal issues. An equally interesting framework is that of information discernment (a sub-theme within information literacy) which will also be discussed. The next section outlines the development of these information literacy models, theories and research.

\section{Information literacy and the sub-set information discernment}

Although a complete history of information literacy remains to be written. It is commonly recognised that the concept of Information literacy, was first coined in 1974 by Paul Zirkowski (Whitworth, 2020b). Information literacy has developed in numerous ways to move beyond a set of normative skills which enable finding, evaluating and using information, to a much more complex concept involving higher order thinking within a social context. Information literacy has developed in a number of directions from individualised practice-based models such as ACRL new framework (2016), the SCONUL Seven Pillars Model (2013), ANZIIL (Bundy, 2004), to models which are research based and have a socio-cultural focus such as Lloyd (2017)) and more complex educational frameworks such as ANCIL (Secker and Coonan, 2013) to interdisciplinary frameworks such as information discernment (Wong et al, 2021). Many research studies have noted the value of information literacy training for example, Jacobson and Mackey (2013), Jacobson et al. (2018) and Mackey (2020); Shenton and Pickard (2012; 2014a; 2014b); Walton and Hepworth (2011; 2013); Walton et al. (2018).

Of particular interest is the notion of Metaliteracy (a practitioner model) promoted by Jacobson and Mackey (2013), Jacobson et al. (2018) and Mackey (2020) which draws in part from notions of critical information literacy proposed by Elmborg (2006). This model highlights four goals with 34 related sub-goals (Jacobson et al., 2018). The goals are expressed normatively, as behavioural (what students should be able to do to successfully complete learning activities), cognitive (what students should know in order to be successful learners and this has some resonance with Bloom et al's (1956) taxonomy in particular, comprehension, application and evaluation in order to become critical thinkers), affective (changes in emotion during learning) and metacognitive (what learners think about their own thinking characterised as a reflective process) (Jacobson et al., 2018). In using the technical language of higher education teaching and learning this, as Lloyd (2016) and Marzal and MartinezCardama (2020) remark, places Metaliteracy firmly in the academic context. Metaliteracy is based on the assumption that 'traditional' models of information literacy do not address the changing information landscape brought about by the rise of social media. The claim, made several times by Mackey and Jacobson, (2011), Jacobson and Mackey (2013), Jacobson et al. (2018) and Mackey 
(2020) is that Metaliteracy offers a reframing of information literacy, yet as Lloyd (2016:n.p.) observes, "while [Jacobson and Mackey, 2016) are] reporting interesting approaches to supporting or developing an information literacy curriculum with an online focus, [they are] not in reality saying anything new (i.e., student empowerment, active learning and participation, developing students' reflective competency are already part of the broader information literacy discourse)". Mackey maintains that there are revolutionary changes in the information environment. Although this is contested by Fuchs (2017) who notes that although the medium has changed the processes of the message have not. What is not in dispute is the emergence of collaborative technologies such as social media has informed the evolution of Metaliteracy as a "unified construct which supports the acquisition, production, and sharing of knowledge and collaboration in collaborative online communities' (Mackey, 2020, p.207). Where Metaliteracy is truly meta is in the need to evaluate the motivation and form behind information ss that the reader begins to "identify whether or not an online discussion [or indeed any information source] is part of a [recognised expert body] or less clearly defined group of [non]-participants interested in a topic" Mackey and Jacobson (2011, p.74). It is noteworthy that Mackey and Jackobson $(2011$, p.76) accept that "the abilities to [...] access, evaluate, incorporate and use information" remain common threads throughout the models and theories that make up the literacies of information pantheon. However, Marzal and Martinez-Cardama (2020, p.11) in their meta-analysis note that Metaliteracy academic research is "scarce but recent and growing". They observe that conceptual development of Metaliteracy is largely based upon case studies "without a global approach to applied research".

Lloyd's information literacy theory (Lloyd, 2017) based on Schatzki (2000) and developed in Lloyd and Williamson (2008) and Lloyd (2010; 2017) offers a different approach by re-imagining how we view the multitude of literacies identified by Mackey and Jacobson (2014) into a new mid-range theory coined as literacies of information. This theory locates information literacy as a socio-cultural practice that is "enacted in a social setting. It is composed of a suite of activities and skills that reference structured and embodied knowledges and ways of knowing relevant to the context" (Lloyd, 2017, p.94). Lloyd (2010, p.252) argues that information literacy should be seen as an information practice (its sayings, doings and relatings) which exists and is enacted through the social setting and is not "reified and decontextualised skills, cast adrift and remote from the discourse and practices that drive human activity". In other words, information literacy is a contextual way of understanding a situation which involving mobilisation of information of any kind from the codified (for example text or image) to the tacit (unwritten or even unspoken but nevertheless embodied and enacted).

It is argued here that whilst Metaliteracy sits at the psychological end of the information literacy spectrum and literacies of information sits at the socio-cultural end, the information discernment framework (IDF) attempts to bring these considerations together. The empirically grounded Information Discernment Framework outlined below provides an equally nuanced model of the salient factors when people encounter information which are akin to Metaliteracy but derives from different traditions. The strength of the IDF is in its foundation in information behaviour research outwith education (Hepworth, 2004), its testing in both HE (Walton and Hepworth, 2011, p.2013) and school domains (Walton et al, 2018) and its application in successfully analysing preventing violent extremism training programmes (Wong et al, 2021). It is remarkably similar to Metaliteracy although it has developed in parallel. The IDF identifies the social dimension as important but, it is not a practice framework, rather it foregrounds and explains the social, psychological and behavioural states and information source factors involved when people encounter information.

The Information Discernment Framework (Figure 1) uses Hepworth's information behaviour model which emerged from research on informal carers as a foundation (Hepworth, 2004). This work draws upon previous information behaviour research including (but not an exhaustive list) - Kuhlthau (1991); Wilson (1999); Nicholas (2000); Spink et al. (2001). The Framework was initially redeveloped as a means for analysing educational contexts, and verified via the analysis of first year undergraduates' approaches to making judgements about information for an assignment (Walton \& Hepworth, 2011; 2013). 
FIGURE 1: Information Discernment Framework (Walton 2017, p139 adapted from Walton and Hepworth's information literacy behaviour model, 2011, p470 itself based upon Hepworth, 2004, p.705)

\title{
[HERE]
}

\begin{abstract}
Walton (2017, p.139) argues that information discernment takes into account and highlights the importance of the 'range of norms, roles and tasks [that] contextualise and shape a person's interaction with information sources'. Additionally, the information discernment process is 'associated with different psychological states which have an impact on information behaviour and which are, in turn, moderated by the affordances (character and behaviour) of the information sources that they used' (Walton, 2017,p.139). Information sources can be of any kind, from databases or images to people. When people encounter information sources, the interactions occur iteratively and may enable the accomplishment of a task. Factors affecting the norms which shape the ways information is received include the context (such as college or workplace) the persons role (such as teacher or student) and the nature of the task (such as solving an intellectual or practical problem). As a result of encountering information, new and/or a change in behaviour may occur. This, however, will only occur when the individual has undergone a cognitive process which may involve experiencing a new knowledge state after combining new with existing knowledge. This takes place through a process of comprehension, analysis, application and synthesis. A metacognitive state could also be reached where individuals reflect on the information encounter and the new knowledge they have gained. These cognitive and metacognitive states are underpinned by the style state (including an individual's self-efficacy and motivation) and affective state (emotions) which also has a part to play in the information encounter. For example, enjoying the activity (affective state) and liking its interactive nature such as working in a team (a positive style state).
\end{abstract}

The focus of this paper is in the articulation of the 'prior/new knowledge state' (Walton, 2017; Walton et al., 2018a) illustrated in Figure 2.

FIGURE 2: 'Articulation' of the knowledge state (Walton 2017, p150)

[HERE]

This part of the Information Discernment Framework identifies the importance of worldview in underpinning prior knowledge and foregrounds the strong effect it has on shaping a person's beliefs. Kahan et al (2012) found that accomplished scientists' views of climate change were shaped by their political affiliations, not scientific prior knowledge. They found that Democrat scientists were more likely to accept man made climate change whereas Republican scientists tended towards climate change denial. This example of motivated reasoning indicates that even the most intellectually able will tend to seek out and cherry-pick the information which fits their worldview. The third factor identified as shaping worldview is that of 'epistemic beliefs'. According to (Trevors et al., 2017), people divide into two distinct types: those that are comfortable dealing with contradictory information and exhibit curiosity, and those who are less comfortable in dealing with contradictory information, believing knowledge to be constituted of unchanging facts. The fourth factor shaping worldview is confirmation bias (for example, Campbell et al., 1960; Taber and Lodge, 2006; Kappes et al., 2020) where, for example, people read news stories that confirm their beliefs rather than contradict them.

Self-efficacy defined as 'the conviction that one can successfully execute the behaviour required to produce the outcomes' (Bandura 1977, p193) constitutes another significant factor in relation to information literacy (Kurbanoglu and Buket, 2006; Ross et al, 2016; Hatlevika et al., 2018). Given that information discernment is a sub-set of information literacy it can be assumed that those who display high levels of information discernment may also have high levels of self-efficacy. Selfefficacy is also relevant because of its relation to the ways in which we deal with stressful situations (Floyd et al., 2000). Floyd et al, (2000) in their meta-study of Protective Motivation Theory (PMT) which they define as "motivation toward protection results from a perceived threat and the desire to avoid the potential negative outcome". They note the statistically significant positive relation between 
self-efficacy and addressing perceived threats - indicating that, "changes in protective behaviours corresponded with the psychosocial variables [such as self-efficacy] included in the (PMT) model. Self-efficacy is also considered an antecedent of the challenge and threat stress state (Turner et al., 2013) discussed below

This is beneficial in terms of cognition (Zimmerman, 2000). What we do not know is whether this also encompasses the psychophysiological (the relationship between mental and physical processes), especially the effects on emotions and stress. Despite the plethora of research on cognitive aspects of information behaviour (see Case and Given, 2016), information literacy (Thompson and Lathey, 2013) and psychology (Zyoud et al., 2018) in relation to exposure to mass-digital media and digital information, the psychophysiological impact of such interaction upon healthy individuals remains poorly studied (Marin et al.., 2012). Psychological responses have been measured to determine whether exposure to mass media related terrorist events influence the reporting of stress symptoms (Schlenger et al., 2002; Schuster et al., 2001), yet the combined physiological and cognitive evidence remains scarce. Presently, few studies have investigated the effects of viewing the news and the physiological consequences to stress (for example Deal et al, 2017; Ragonesi and Antick, 2008). None have investigated psycholophysiological aspects of stress in relation to level of information literacy.

\section{Challenge and threat}

The BioPsychoSocial Model (BPSM) of Challenge and Threat may aid understanding the physiological antecedents that could underpin psychological states associated with information literacy. The BPSM has some resonance with Wilson's notion of 'stress/coping' (Wilson, 1999), uncertainty (as identified by Kuhlthau, 1991), the affective state (as highlighted by Hepworth, 2004 and Walton and Hepworth, 2011) and how they underlie the information seeking process (Wilson, 1999). The BPSM theorises that individuals respond to stressful situations with either an adaptive (challenge) or maladaptive (threat) response, dependent upon an individual's often unconscious evaluation of the situation (Blascovich and Mendes, 2000). For example, a challenge state will occur if an individual evaluates their resources (i.e., self-efficacy, perceptions of control, and goal orientation) to be sufficient to meet the perceived demands of the situation. Whereas a threat state will ensue if these resources are not sufficient to meet the perceived demands. These evaluations can lead to both mental and physical health implications including poor mental health and cardiovascular disease (Dienstbier, 1989; Seery, 2011).

There are several key challenge and threat physiological states which denote healthy and unhealthy responses respectively. An increase in sympathetic-adreno-medullary (SAM) activation during a challenge state results in a greater release of adrenaline and noradrenaline, causing an increase in heart rate (HR) and cardiac output (CO), and a decreased total peripheral resistance (TPR) (Seery, 2011). CO is the amount of blood pumped from the heart per minute, whereas TPR is a measure of the constriction/dilation of the blood vessels (Jamieson et al., 2012). Therefore, in a challenge state, the stress response reflects efficient physiological reactivity (Blascovich et al., 2011), with more blood being pumped from the heart and travelling through wider blood vessels, leading to an enhanced delivery of glucose and oxygen to the brain, muscles, and vital organs. In contrast, in a threat state SAM activity is supplemented by pituitary-adreno cortical (PAC) activity, releasing cortisol into the bloodstream (Blascovich et al., 2004). Cortisol inhibits the effects of adrenaline and noradrenaline thus dampening the beneficial cardiovascular responses observed within a challenge state (Meijen et al., 2020). So an increase in HR is evinced alongside decreased or stable CO, and increased TPR. Therefore, a threat state is characterised by a less efficient and unhealthy cardiovascular response; cortisol can cause long-term issues for somatic and mental well-being (Gaab, et al., 2005). Psychologically, a challenge state is associated with more positive emotions and lower levels of anxiety, whereas a threat state dissimilarly produces more negative emotions and increased levels of anxiety (Turner et al., 2012).

High self-efficacy, arguably apparent for an individual who possesses high levels of information discernment because it is a sub-set of information literacy, is an essential cognitive antecedent of a challenge state (Jones et al., 2009). That is, for an adaptive challenge response to stress to occur, an 
individual should believe in their ability to execute behaviours to perform well. Therefore, should a highly discerning individual encounter misinformation, it is highly likely that they will respond to that misinformation with an adaptive challenge state and a healthier stress response, as they possess a high-level of belief and perceived control concerning their ability to appropriately discern that information.

The positive cognitive effects of IL are well-known as shown above, yet the psychophysiological outcomes have not been researched hitherto. Therefore, with the current climate of fake-news and the Infodemic, it is essential to understand how misinformation (of whatever kind) is affecting individual's psychophysiological health and whether information discernment level has any influence on an individual's response to to misinformation within a healthy and adaptive challenge state.

In summary, the purpose of this study is to determine to what extent a person's psychophysiological well-being is affected by misinformation and whether their level of information discernment has any positive or negative effect. It is argued that those who demonstrate high levels of information discernment will have a more positive emotional and adaptive stress reaction to misinformation than those with low levels of information discernment. To our knowledge this is the first study of this kind.

\section{Methodology}

\section{Participants}

Forty-eight $18-24$ year old males $(\mathrm{M}=19.73$ years, $\mathrm{SD}=2.04$ years $)$ took part. This age group was chosen because, people aged 18-24 were the most likely users of the Internet at the time of the experiment and remain so (ONS, 2021, Table 2B). Males were selected in order to control for the variability in the ways that males and females engage with ICT (Ford, 2004; Siddiq and Scherer, 2019). Recent research also indicates that males are more likely to seek out misinformation than females (OfCom, 2021). Additionally, the experiment was designed to assess Cardio-Vascular (CV) responses continuously, while participants were also reading the articles. There is evidence of sex differences between hypothalamic-pituitary-adrenal (HPA) axis responses to stress (Kudielka and Kirschbaum, 2005) and physiological responses (Krantz et al., 2004). Furthermore, arousal and attentional responses can differ (Bangasser et al., 2019).

\section{Design}

A between-group experimental design was implemented to assess how different levels of information discernment influenced the stress response of individuals performing a motivated performance task following misinformed stigmatisation (experimental group) or non-stigmatisation (control group). That is, participants were randomly and blindly assigned to either a high-stigma $(n=24)$ or lowstigma $(n=24)$ group during the delivery of task instructions to ensure equal probability of inclusion and minimise bias (Bryman, 2016).

This device of misinformed stigmatization has been used previously in a number of challenge and threat experiments (e.g., Behnke and Kaczmarek, 2018; Turner et al., 2012; Blascovich et al., 2000). Stigma has been used to provoke threat in motivated performance situations by influencing demand and resource evaluations directly (Blascovich et al., 2000). Thus, this design enabled the investigation into whether misinformed stigmatization prompts threat responses for individuals who cannot appropriately discern dis-information.

The nature of the misinformed stigmatisation employed here was religious extremism. At the time of devising the experiment, the threat of religious extremism was highly topical and frequently in the news (Global Extremism Monitor, 2017) and so was chosen as a useful basis for the presentation of dis-information. In this experiment participants were led to believe that they were working with a fellow student to win a prize. In fact this 'fellow student' was a 'confederate', a student actor working for the research team.

For the control group (non-stigmatized) participants were simply told they were working with a fellow student. 
For the experimental group (misinformed stigmatization) participants were informed by the Research Associate conducting the experiment that the fellow student was a religious extremist. This idea or unit of information (Bateson, 1972) was the actual misinformation, or more correctly, disinformation (Lewandowsky and Yesilada, 2021) to which participants were exposed.

To further prime stigma, all participants were provided with online texts to read on the subject of religious extremism.

\section{Stress Manipulation and Task}

Participants were asked to complete a competitive word search task to provide them with a motivationally relevant situation, required to assess challenge and threat states (Behnke and Kaczmarek, 2018).

Therefore, it was felt that the choice of online texts pertaining to religious extremism plus the deception and impossible to finish task would create enough mild stress to generate meaningful data to measure challenge and threat responses. As a precaution we used the Religiosity Scale (Huber and Huber, 2012) to screen for potential high, or extreme, religious views in the actual participants to avoid contamination of results.

\section{Measures}

\section{Information discernment level}

The information discernment questionnaire (IDQ) asked participants about how they consumed news, their thoughts about knowledge and how they made judgements about information. The questionnaire was based on previous research questionnaires validated by Walton and Hepworth (2011 and 2013); Johnston and Walton (2014); Cleland and Walton (2012) and inspired by studies from Campbell et al., (1960) and Trevors et al. (2017).

Likert scales were used because they are easy to develop and participants enjoy filling in these scales, the advantage being that if participants like what they are doing they are more likely to give considered rather than perfunctory answers (Robson and McCartan, 2016). The disadvantages of these scales are that they are indirect indicators rather than direct measures of any issues (Bryman, 2016). It is also recognised that those with low levels of information literacy (especially males) tend to overreport their capabilities (Gross and Latham, 2012). To determine a high and low-level of discernment, the interquartile range was calculated from the data collected via the information discernment questionnaire. For the purposes of this study, a value of 48.5 was found to be the median score, therefore any values lower than this were considered as low discernment, and any values higher were considered high discernment.

\section{Challenge and threat Cardio-Vascular (CV) indices and psychometrics}

A Finometer Pro (Finapres Medical Systems, Enschede, The Netherlands) was used to collect standard measures for CV data (including Cardiac Output (CO), and Total Peripheral Resistance (TPR) measures from participants to calculate challenge and threat indices (CTI) (Turner et al, 2013). For a detailed breakdown for these measures please see Appendix 1.

In addition, these complementary data were gathered:

Challenge and Threat psychometric data (Turner et al, 2013) to provide an assessment of challenge and threat self-reported appraisals and their motivation to complete the task;

The Positive Affect Negative Affect Survey (PANAS - Watson et al., 1988) was used to assess affective responses of participants before completing the task.

Self-efficacy using a scale created by Johnston and Walton (2014) adapted from Bandura (2006) because it has an association with both information literacy (Kumar and Edwards, 2013), challenge/ threat state (Blascovich and Mendes, 2000) and protection motivation (Floyd et al, 2000). All employ Likert scales (The experimental protocol is summarized in Figure 3, see Appendix 1 for more detail). 
The experiment employed a number of deceptions and because of this full ethical clearance for this study was obtained via the PI's institution. Participants were fully debriefed immediately after the experimental protocol was completed. It was at this debrief that participants learnt of the deception.

FIGURE 3: Experimental protocol

[HERE]

\section{Results}

\section{Information Discernment Questionnaire (IDQ)}

High-level information discerners scores ranged between 49-58 and low-level information discerners between 40 and 48 (median=48.5). Scores were confirmed as statistically significantly different between high and low-level information discerners: $t$-value is 8.43314 ; $\mathrm{p}$-value is $<.00001$. The result is significant at $\mathrm{p}<.05$. Overall this implies that there are significant psychological differences in the ways in which people experience information. Those in the high-level range report: less susceptibility to conformation bias, a greater level of curiosity, being less likely to cherry-pick evidence and use a greater range of criteria to evaluate information.

Drilling down into the data in more detail revealed nuanced results not revealed in the overall scores. Although the assumptions of normality were violated, homogeneity of variance was met, therefore a one-way MANOVA was conducted for the first sub-section as the MANOVA is fairly robust to deviations from normality. The test indicated that there was not a significant difference between the way in which participants answered questions 1-2 based upon their ID level, (Wilks' $\Lambda=.891, \mathrm{~F}$ (2, $45)=5.053, p=.074 \eta 2 p=.109$, observed power $=.516$ ). A second one-way MANOVA was conducted for the second sub-section. Again, assumptions of normality were violated, but homogeneity of variance was met. This indicated that there was an underlying weak difference in confirmation bias between high and low level information discerners.

The test indicated that there was a significant difference between the way in which participants answered questions 3-8 based upon their ID level, (Wilks' $\Lambda=.606, \mathrm{~F}(6,41)=4.451, \mathrm{p}<.01 \eta 2 \mathrm{p}=$ .394 , observed power $=.968)$. Examination of the univariate effects showed significant interaction effects for question $3(\mathrm{~F}(1,46)=8.189, \mathrm{p}<.01, \eta 2 \mathrm{p}=.151$, observed power $=.800), 6(\mathrm{~F}(1,46)=$ $5.163, \mathrm{p}=.028, \eta 2 \mathrm{p}=.101$, observed power $=.604)$, and $8(\mathrm{~F}(1,46)=4.182, \mathrm{p}=.047, \eta 2 \mathrm{p}=.083$, observed power $=.517)$. This confirms that high-level information discerners differ significantly in their epistemic beliefs in that they report a more flexible, curious and open-minded outlook on knowledge.

A further MANOVA was conducted for the final subsection of the IDQ. The assumptions of normality and homogeneity of variance and covariance were met. The MANOVA indicated a statistically significant difference in the way in which participants answered questions $9,10,11,12$ and 14, (Wilks' $\Lambda=.575, \mathrm{~F}(6,41)=5.053, \mathrm{p}<.01 \eta 2 \mathrm{p}=.425$, observed power $=.98$ ). Examination of the univariate effects showed significant interaction effects for question $9(\mathrm{~F}(1,46)=5.706, \mathrm{p}=$ $.02, \eta 2 p=.110$, observed power $=.65)$, question $10(\mathrm{~F}(1,46)=8.543, \mathrm{p}<.01, \eta 2 \mathrm{p}=.157$, observed power $=.81)$, question $11(\mathrm{~F}(1,46)=6.022, \mathrm{p}=.02, \eta 2 \mathrm{p}=.116$, observed power $=.67)$, question 12 $(\mathrm{F}(1,46)=5.731, \mathrm{p}=.02, \eta 2 \mathrm{p}=.111$, observed power $=.65)$, and question $14(\mathrm{~F}(1,46)=13.828, \mathrm{p}$ $<.01, \eta 2 p=.231$, observed power $=.95)$. This further substantiates the assertion that high-level information discerners report significantly more scepticism in their evaluation of information and look for a range of signals to discern quality and that they tend not to cherry pick evidence. (ie less prone to motivated reasoning).

The results, in short, confirm that high-level information discerners are: more curious, tend to use multiple sources to verify information, are more likely to be sceptical about information on search engines such as Google, do not regard the first results page as the most trustworthy information and are cognisant of the importance of authority. Conversely, low information discerners are significantly less likely to be aware of these issues. 
Differences between challenge and threat responses, emotions, and self-efficacy for ID levels and group

Initially, a paired samples t-test was conducted with the averaged final minute of baseline HR and the averaged 2-minute post-task thinking time HR. There was a significant increase in HR, t (47) $=-1.98$, $\mathrm{p}=.05$, from the last minute of baseline $(\mathrm{M}=72.46 \mathrm{bpm}, \mathrm{SD}=10.35)$ to the 2-minutes of thinking time $(\mathrm{M}=73.95 \mathrm{bpm}, \mathrm{SD}=10.04)$. A significant increase in HR indicates task engagement (Seery, 2011). In addition, participants also indicated high levels of task effort $(\mathrm{M}=5.25, \mathrm{SD}=0.81) \mathrm{t}(47)=$ $44.79, \mathrm{p}<.001$, and motivation $(\mathrm{M}=4.96, \mathrm{SD}=0.73) \mathrm{t}(47)=47.18, \mathrm{p}<.001$, prior to the task. In sum high-level information discerners tend to show more motivation in task completion.

The two-way MANCOVA indicated that there was a significant difference between level of ID and group (Wilks' $\Lambda=.473, \mathrm{~F}(10,32)=3.568, \mathrm{p}=.038 \eta 2 \mathrm{p}=.527$, observed power $=.971$ ). Examination of the univariate effects showed significant interaction effects for post positive emotions $(\mathrm{F}(1,41)=1.546, \mathrm{p}<.05, \eta 2 \mathrm{p}=.100$, observed power $=.551)$, and post demand and resource appraisals $(\mathrm{F}(1,41)=17.918, \mathrm{p}=.005, \eta 2 \mathrm{p}=.175$, observed power $=.821)$. In sum, stigmatised individuals (those exposed to disinformation) with higher levels of information discernment significantly appraised the situation with more of a challenge response and with higher levels of positive emotions than individuals with lower levels of information discernment.

TABLE I - Means and S.D. of key variables for stigmatized group [HERE]

Although not significant, there were some key mean differences observed within the data (see Table I). When stigmatised, higher discerning individuals possessed higher levels of self-efficacy (Mdifference $=6.18), \mathrm{CO}$ reactivity $($ Mdifference $=0.36$ ), and Challenge and Threat Index - CTI $($ Mdifference $=1.16)$, and a lower TPR reactivity (Mdifference $=-19.22$ ). Higher CO reactivity and CTI accompanied by lower TPR reactivity scores indicate more adaptive challenged responses. Therefore, on average, higher discerning individuals felt more self-efficacious and more challenged than individuals with low information discernment when provided with misinformation.

The data from the IDQ indicates that there are statistically significant differentiating psychological and emotional characteristics and patterns associated with high and low information discernment. There are indications of differences in physiological characteristics but these are not statistically significant. These results partially confirm the expectations of the hypothesis and the psychological aspects, in particular, reflect earlier work by Walton and Hepworth (2013).

\section{Discussion}

The results from the IDQ questionnaire appear to indicate that hypothesis H1 is demonstrated. There are apparent differences in the way that participants report the ways in which they make judgements about information. Those with a high-levels of ID are more likely to report having an additional cluster of psychological states including a more sceptical approach to evaluating information which agrees Walton et al. (2018), are open to considering alternative views which supports epistemic beliefs work by Trevors et al. (2017) and will not indulge in selective cherry picking of evidence to support a view, aligning with Kahan et al. (2012). The view put forward by Lewandowsky et al. (2012) and supported by Walton et al (2018) that people have a default position of trust is not necessarily upheld. It therefore begs the question whether inoculation theory should adopt a more nuanced approach and not assume that people tend to be initially passive and trusting in their information encounters.

Hypothesis (H2) appears to be partially upheld implying a relationship between psychological and physiological reactions to misinformation in a mildly stressful situation. Does this perhaps add a new dimension to Lloyd's concept of embodied knowledge in that people appear to have a measurable physiological as well a cognitive reaction to information? What is concerning here is that, some participants (those with a low-level of information discernment) appear to be vulnerable to misinformation in both their psychological and physiological response. Given that those with low 
level of information literacy can be moved to higher levels (Walton, 2017) it demonstrates the need for training of some sort whether it be inoculation (Cook et al, 2017; Lewandowsky and Yesilada, 2021), Metaliteracy (Mackey, 2020), information literacy (Secker and Coonan, 2013) or a combination.

High-level information discerners appear to be significantly more likely to report that they look for more than one source of information. This further corroborates the curiosity issue and more general views regarding what makes a person information literate (Shenton and Pickard, 2014b; Mackey and Jacobson, 2011; Jacobson and Mackey, 2013; Jacobson et al, 2018; Mackey, 2020). This indicates that low information discerners have a narrower idea of how to go about evaluating information and the need to consult multiple sources - a potential weakness in critical thinking that may lead to conspiracy theory ideation (Douglas et al, 2019). The reported willingness of low discerners to trust the first page of results is in line with many previous reports which have revealed the poor search abilities of young people (for example Pickard et. al., 2014).

Most respondents indicated an awareness that what is on search engines such as Google is not always true. However, there is a nuanced and highly statistically significant pattern, high-level information discerners are far more likely to strongly disagree with the statement than low discerners. This lack of critical awareness to make credibility judgements (Keshavarz, 2020) could make low-level information discerners vulnerable to misinformation of any material whether it be health related, extremist or conspiracy forming information as noted by Douglas et al. (2019). In a linked statement regarding the authority of sources participants there was a marked difference in their responses. The notion of authority is as a key criterion in making well-calibrated judgements about information (for example ACRL, 2016). Again statistically significant differences between high and low discerner responses reveals stark difference in how the engage with information. High-level information discerners are more likely to indicate certainty in their responses than low information discerners. This perhaps underlines the observation that high-level information discerners are significantly more likely to report that they will consider a range of criteria when making judgements about information indicating greater curiosity (Trevors et al, 2017). The fact that authority is a neglected feature for many information discerners confirms the ACRL (2016) position that the notion of authority is an important factor in information literacy training.

Those participants with high levels of information discernment were more likely to exhibit a more challenge-like state, cultivating in more adaptive and healthier cardiovascular, cognitive, and emotional responses (Dienstbier, 1989; Seery, 2011). Conversely, those with low levels of information discernment will experience a threat-like state with a more negative and unhealthier cardiovascular, cognitive, and emotional responses (Dienstbier, 1989; Seery, 2011). This reflects earlier work which showed that those with a higher level of information discernment are more likely to exhibit a positive affective state (Walton and Hepworth, 2011). It also articulates the notion of stress/coping noted in Wilson's model (1999) and Kuhlthau's (1919) notion of uncertainty, indicating that these states do play a significant part in information behaviour in that higher levels of uncertainty mean a threat state is more likely which could prove detrimental to a persons health (Dienstbier, 1989; Seery, 2011). Furthermore, this supports (Mackey and Jacobson, 2013) observation that emotion plays an important role in becoming Metaliterate.

It is interesting to note that, there are minimal differences in participants stated thinking around confirmation bias (Kappes et al., 2020). This perhaps indicates that though individuals can be highly nuanced in their information discernment of non-news sources of information they will still be drawn to news media that reflect rather than contradict their worldview. This also plays into the notion of motivated reasoning (Kahan et al., 2012) in that, even though individuals may report being very good at making judgements about information they may still be susceptible to cherry-picking the good quality information to confirm a view rather than consider all sides of an argument. Although, highlevel information discerners views on knowledge may be more flexible (as exhibited through their epistemic beliefs as noted by Trevors et al., 2017) and, as a result, their responses on how they analyse information may mitigate this weakness. This perhaps indicates a more subtle issue that information literacy training such as those proposed by for example, Jacobson et al. (2018) and 
Mackey (2020) should pay greater attention to discussing with participants the perils of only selecting information which supports rather than alternative perspectives of an argument (Kahan et al., 2012).

\section{Implications}

Stress, as a component of information literacy has not been discussed hitherto. The results indicate that there are potentially physiological as well as psychological consequences to having a low-level of information discernment manifest as a negative reaction to stress. It appears that this category of individual will not only tend to make sub-optimal judgements (especially when exposed to misinformation) but will feel a heightened sense of anxiety in an unhealthy stress response. From a practitioner perspective, information literacy training has the potential not only to enable people to make better judgements about information and misinformation but also to alleviate negative stress responses and also promote a positive emotional reaction.

However, although the results indicate that some students who attend information literacy sessions may not already exhibit high-levels of information discernment others may well do. This means a class cannot be treated as one homogenous group. It may be useful to use the IDQ as a diagnostic test to determine where students are on the ID scale. This may help to design more targeted learning and teaching interventions. Context is an important factor and any teaching should match the context in which students are found (Loyd, 2010; 2017). This may be very useful in the context of collaborative working noted by (Mackey, 2020) to distribute those who are high-level information discerners amongst a class in order to harness their skills more productively. Additionally, there appears to be a real danger that very able students may cherry-pick evidence with their newly found information literacy skills. This tendency in some needs to be discussed perhaps via the metacognitive reflection exercises promoted by Mackey and Jacobson (2011), Jacobson and Mackey (2013; Jacobson et al., (2018) and Mackey (2019).

From a societal perspective, it is apparent that potentially at least $50 \%$ of the male population may lack the critical thinking skills to carry out a well-calibrated assessment of misinformation - this clearly supports the view of Douglas et al (2019) that more work on the role of critical thinking in preventing conspiracy theory and extremist ideation is needed and may diminish the velocity at which misinformation travels the digital sphere noted by (Vosoughi et al., 2018). Again the role of context is vital here (Lloyd, 2010; 2017). Given the critical thinking aspects of Metaliteracy, perhaps introducing Metaliteracy learning and teaching methods into compulsory education as early as possible is necessary so that this approach is not privileged for those in higher education only. Additionally, because of the formal and informal decision making nature of information literacy (Whitworth (2020a) and if we are to take the DDCMS (2021) seriously and make public libraries central in the fight against online misinformation; it is argued that Metaliteracy, information literacy and/or inoculation theory methods could form the central plank of a training programme for public librarians and, in turn, their customers - the general public.

\section{Limitations}

A small sample size of 48 participants provided limited power for analysis, particularly as this sample was divided into control and experimental groups $(n=24)$ and high and low ID groups $(n=24)$. This is perhaps why statistical significance was not achieved within many of the tests. Furthermore, misinformation was provided within the context of task instructions and the articles read by participants were taken from news websites. However, social media, such as Twitter, has now become the key place for young adults to access news sources (Veinberg, 2015). Therefore, information sourced from and presented via social media sites (e.g., a Twitter or Facebook feed), may provide a more ecologically valid approach to this specific methodology. Finally, challenge and threat responses provide us with an insight into how individuals are feeling at that specific time and situation. As such, it is difficult to make assumptions, based upon the current data collected, that high-level discerners will always respond in a more adaptive way than low discerners when faced with misinformation and that higher ID levels will promote long-term health benefits. Repeated measures and/or further assessment methods (e.g., cortisol testing) of stress responses may provide evidence to further 
emphasize the physical and psychological health implications of misinformation and provide insight into the long-term benefits of possessing high levels of ID.

\section{Conclusions}

In summary high-level information discerners report a tendency to be: more curious about information; cognisant of authority, ie inspect the credentials of the author; interrogate a piece of information methodically, attend to all aspects presented to them; tend to use multiple sources to verify information, more likely to be sceptical about information on search engines such as Google; do not regard the first results page as the most trustworthy information; regard knowledge as not fixed but changing and recognise that knowledge can be contradictory at times. Additionally, higher discerning individuals appear to respond to stigmatised dis-information in an adaptive (challenged) way and with a positive emotional reaction. This may mean that when a person is looking for information in a stressful situation (e.g., health information) those who have high levels of information discernment may be more likely to make well-calibrated judgements about the information they find which, in turn may help them to make more appropriate decisions about the information they use. Conversely, those with low information discernment may be more likely to make sub-optimal decisions about the quality of the information they encounter because they lack the tools to interrogate its validity are likely to be less emotionally positive and feel their stress in a maladaptive (threatened) way.

The potential link between high levels of information discernment, emotion and challenge stress response when encountering stigmatised misinformation indicates that there are clear benefits in having a population of high-level information discerning individuals. This theoretical link between the physiological and psychological is worthy of more research with a larger cohort to determine whether this can be generalised more widely. This upholds the significance that stress/coping (an element of Wilson's information behaviour model, 1991) and affective factors (Kuhlthau, 1991; Hepworth, 2004; Walton and Hepworth, 2011; 2013) play in the information behaviour process. This indicates a critical need to employ effective information literacy (Secker and Coonan, 2013) or Metaliteracy teaching and learning methods (Mackey and Jacobson, 2019), to raise information discernment levels from low to high to combat the effects of misinformation. The results discussed here indicate that those with low levels of information literacy (information discernment in particular) may be far more susceptible to misinformation, not just cognitively but also emotionally and physiologically. This has profound implications for society by providing a further indication of the dangerous effects of misinformation such as that propagated in conspiracy theories, extremist material and the so called Infodemic.

\section{References}

American College and Research Libraries (ACRL) (2016). Framework for information literacy for higher education. Available at: http://www.ala.org/acrl/standards/ilframework (Accessed 30th November 2017)

Bandura, A (1977). Self-efficacy: Toward a unifying theory of behavioral change. Psychological Review, Vol. 84 No. 2, pp. 191-215.

Bandura, A. (2006). Guide for constructing self-efficacy scales. In, Pajares, F. and Urdan, T. (eds.). Self-Efficacy Beliefs of Adolescents (pp. 307-337). Information Age Publishing.

Bangasser, D. A., Eck, S. R., and Sanchez, E. O. (2019). Sex differences in stress reactivity in arousal and attention systems. Neuropsychopharmacology, Vol. 44 No. 1, pp. 129-139.

Bateson, G. (1972). Steps to an Ecology of mind Collected essays in anthropology, Psychiatry, evolution, and Epistemology. London: Jason Aronson Inc.

Behnke and Kaczmarek, (2018). Successful performance and cardiovascular markers of challenge and threat: A meta-analysis. International Journal of Psychophysiology, Vol. 130, pp. 73-79.

https://doi.org/10.1016/j.ijpsycho.2018.04.007 (accessed 23 July 2021) 
Belkin, N. J. (2005). Anomalous state of knowledge. In: Fisher, K. E., Erdelez, S. and McKechie, L. E. F. (eds.). Theories of information behavior. Assist Monograph Series. Medford: Information Today, Inc., pp. 44-48.

Blascovich, J. and Mendes, W. B. (2000). Challenge and threat appraisals: The role of affective cues. In J. Forgas (Ed.) Feeling and thinking: The role of affect in social cognition (pp. 59-82). Paris: Cambridge University Press.

Blascovich, J., Seery, M. D., Mugridge, C. A., Norris, R. K., and Weisbuch, M. (2004). Predicting athletic performance from cardiovascular indexes of challenge and threat. Journal of Experimental Social Psychology, Vol. 40 No. 5, pp. 683-688.

Blascovich, J., Mendes, W.B., Vanman, E. and Dickerson, S. (2011). Social Psychophysiology for Social and Personality Psychology. London: Sage.

Bloom, B. S., Engelhart, D., Furst, E. J., Krathwohl, D. A. and Hill, W. H. (1956). Taxonomy of educational objectives: the classification of educational goals: handbook 1: cognitive domain. New York: David McKay Company Inc.

Bogardus, E. S. (1933). A social distance scale. Sociology and Social Research. Vol. 17, pp. 265-271.

Bryman, A. (2016). Social research methods (5th edn.). Oxford: Oxford University Press.

Bundy, A. (2004). Australian and New Zealand information literacy framework: principles, standards and practice. (2nd edn.). Adelaide: Australian and New Zealand Institute for Information Literacy. https://www.utas.edu.au/ data/assets/pdf file/0003/79068/anz-info-lit-policy.pdf (accessed 23 July 2021)

Bytwerk, R. L. (2015). Believing in "Inner Truth": The Protocols of the Elders of Zion in Nazi Propaganda, 1933-1945. Holocaust and Genocide Studies, 29 (2) pp.212-229

https://doi.org/10.1093/hgs/dcv024 (accessed 23 July 2021)

Campbell, A, Converse, P. E., Warren E. Miller, W. E. and Stokes, D. E. (1960). The American Voter. New York: John Wiley.

Case, D. O. and Given, L. M. (2016). Looking for information: a survey of research on information seeking, needs and behavior (4th edn.). Bingley: Emerald.

Cleland, J. and Walton, G. (2012). Online peer assessment: helping to facilitate learning through participation. Journal of Learning Development in Higher Education, 4

Cook J, Lewandowsky S, Ecker U. K. H. (2017). Neutralizing misinformation through. inoculation: Exposing misleading argumentation. techniques reduces their influence. PLoS ONE, 12(5): e0175799. https://doi.org/10.1371/journal.pone.0175799 (accessed 23 July 2021)

Deal, C., Bogdan, R., Miller, J. P., Rodebaugh, T., Caburnay, C., Yingling, M. and Lenze, E. J. (2017). Effects of Cable News Watching on Older Adults' Physiological and Self-Reported Stress and Cognitive Function. The International Journal of Aging and Human Development, Vol. 87 No. 2, pp.111-123. https://pubmed.ncbi.nlm.nih.gov/29139320/ (accessed 27 May 2020).

Dienstbier, R. A. (1989). Arousal and physiological toughness: implications for mental and physical health. Psychological Review, Vol. 96 No. 1, p. 84.

Douglas, K. M., Uscinski, J. E., Sutton, R. M. et al (2019). Understanding Conspiracy Theories. Advances in Political Psychology, Vol. 40, Suppl. 1: 3-35. https://doi:10.1111/pops.12568 (accessed 23 July 2021)

Edwards, L. Stoilova, M., Anstead, N., Fry, A., El-Halaby, G. and Smith M. (2021) Rapid Evidence Assessment on Online Misinformation and Media Literacy: Final Report for Ofcom. Available at: www.ofcom.org.uk (accessed 23 July 2021) 
Elmborg, J. (2006). Critical information literacy: implications for instructional practice. Journal of Academic Librarianship, Vol 32, No. 2, pp. 192-199. https://doi.org/10.1016/j.acalib.2005.12.004 (accessed 23 July 2021)

Emmelkamp, J., Asscher, J. J., Wissink, I. B. et al (2020), "Risk factors for (violent) radicalization in juveniules: a multilevel meta-analysis". Aggression and Violent Behavior, Vol. 55 [101489]. https://doi.org/10.1016/j.avb.2020.101489

Fisher, K. E., Erdelez, S. and McKechie, L. E. F. (eds.) (2005). Theories of information behavior. Assist Monograph Series. Medford: Information Today, Inc.

Floyd, D. L., Prentice-Dunn, S. and Rogers, R. W. (2000). Meta-Analysis of Research on Protection Motivation Theory. Journal of Applied Social Psychology, 30 (2), pp. 407-429.

https://onlinelibrary.wiley.com/doi/abs/10.1111/j.1559-1816.2000.tb02323.x (accessed 23 July 2021)

Ford, N. (2004). Towards a model of learning for educational informatics. Journal of Documentation, Vol. 60 No. 2, pp. 183-225.

Freedland. J. (2017). The Long View of Targeted Fake News. https://www.bbc.co.uk/programmes/b08jb6rt (accessed 23 July 2021)

Freelon, D. and Wells, C. (2020). Disinformation as political communication. Political Communication, 37(2) pp. 145-156.

https://www.tandfonline.com/doi/full/10.1080/10584609.2020.1723755 (accessed 23 July 2021)

Gaab, J., Rohleder, N., Nater, U. M., and Ehlert, U. (2005). Psychological determinants of the cortisol stress response: the role of anticipatory cognitive appraisal. Psychoneuroendocrinology, Vol. 30 No. 6, pp. 599-610.

Global Extremism Monitor (2017). Islamist extremism in 2017: The ten deadliest countries. Tony Blair Institute for Global Change. https://institute.global/sites/default/files/articles/IslamistExtremism-in-2017-The-Ten-Deadliest-Countries.pdf (accessed 23 July 2021)

Great Britain: Digital, Culture, Media and Sport Committee (DCMS) (2018). Fake News. https://www.parliament.uk/business/committees/committees-a-z/commons-select/digital-culturemedia-and-sport-committee/inquiries/parliament-2017/fake-news-17-19/ (accessed 20 June 2018)

Gross, M. and Latham, D. (2012), What's skill got to do with it?: information literacy skills and self-views of ability among first-year college students, Journal of the American Society for Information Science and Technology, Vol. 63 No. 3, pp. 574-583.

Hatlevika, O. E., Throndsenb, I., Loic, M. and Gudmundsdottir, G. B. (2018). Students' ICT selfefficacy and computer and information literacy: Determinants and relationships. Computers and Education, Vol. 102, pp. 103-116. https://doi.org/10.1016/j.compedu.2017.11.011 (accessed 23 March 2019)

Heinstrom, J. (2003). Five personality dimensions and their influence on information behaviour. Information Research, Vol. 9 No. 1. http://informationr.net/ir/9-1/paper/165.html (accessed 27 May 2020)

Hepworth, M. (2004). A framework for understanding user requirements for an information service: defining the needs of informal carers. Journal of the American Society of Information Science and Technology, Vol. 55 No. 8, pp. 695-708.

Hicks, A. (2021). Injecting doubt into inoculation metaphors. Information Literacy Group Blog. https://infolit.org.uk/injecting-doubt-into-inoculation-metaphors-alison-hicks-university-collegelondon/ (accessed 23 July 2021)

Huber, S., and Huber, O. W. (2012). The centrality of religiosity scale (CRS). Religions, Vol. 3 No. 3 , pp. $710-724$. 
Jacobson, T.E. and T.P. Mackey. (2013). Proposing a Metaliteracy Model to Redefine Information Literacy. Communications in Information Literacy, 7(2), 84-91.

Jacobson, T., Mackey, T., O'Brien, K., Forte, F. and O'Keefe, E. (2018). Goals and Learning Objectives: Draft Revision (April 11, 2018). Metaliteracy.org. https://metaliteracy.org/learningobjectives (accessed 23 July 2021)

Jamieson, J. P., Nock, M. K., \& Mendes, W. B. (2012). Mind over matter: reappraising arousal improves cardiovascular and cognitive responses to stress. Journal of Experimental Psychology: General, Vol. 141 No. 3, pp.417-422. https://doi.org/10.1037/a0025719 (accessed 23 July 2021)

Johnston, E. and Walton, G. (2014). Summon, information literacy and 'Step Up To HE'. In E. Coonan (Ed.): Teaching, not telling: Proceedings of the 2nd UK Information Literacy and Summon Day, Manchester Metropolitan University, 25 July 2013, pp. 20-28. Available at:

http://eprints.staffs.ac.uk/1924/1/IL_and_summon_2014_proceedings.pdf (accessed 27 May 2020).

Jones, M., Meijen, C, McCarthy, P. J. and Sheffield, D. (2009). A Theory of Challenge and Threat States in Athletes. International Review of Sport and Exercise Psychology. Vol. 2, No. 2, pp. 161-180, https://doi.org/10.1080/17509840902829331 (accessed 23 July 2021)

Kahan, D. M., Peters, E., Wittlin, M., Slovic, P., Ouellette, L. L., Braman, D. and Mandel, G. (2012). The polarizing impact of science literacy and numeracy on perceived climate change risks. Nature Climate Change, Vol. 2, pp. 732-735. Available at: doi:10.1038/nclimate1547 (Accessed 2nd March 2017).

Kahn, C., Kim, S., Lange, J., Oliphant, J. and Reid, T. (2021). Special Report: Stolen election? Republican lawmakers paralyzed by Trump's false fraud claims. Reuters, U.S. Legal News. February $2^{\text {nd }}$ 2021. https://www.reuters.com/article/us-usa-trump-lawmakers-special-report-idUSKBN2A41CP (accessed 23 July 2021)

Kappes, A, Harvey, A. H., Lohrenz, T., Read Montague, P. Sharot, T. (2020). Confirmation bias in the utilization of others' opinion strength. Nature Neuroscience, Vol. 23, January, pp.130-137 https://doi.org/10.1038/s41593-019-0549-2 (accessed 23 July 2021)

Kennedy, J. (2018). DCU leads $€ 2.4 \mathrm{~m}$ EU project to tackle 'fake news'. Siliconrepublic, 8th November 2018. https://www.siliconrepublic.com/innovation/dcu-provenance-project-fake-news (accessed 17 December 2018)

Keshavarz, H. (2020). Assessing the credibility of Web information by university students: findings from a case study in Iran. Global Knowledge Memory And Communication, Vol. 69 No. 8-9 pp. 681696. https://www.emerald.com/insight/content/doi/10.1108/GKMC-03-2020-0023/full/html (accessed 23 March 2021)

Krantz, G., Forsman, M., and Lundberg, U. (2004). Consistency in physiological stress responses and electromyographic activity during induced stress exposure in women and men. Integrative Physiological \& Behavioral Science, Vol. 39 No. (2), pp. 105-118.

Kuhlthau, C. C., (1991). Inside the search process: information seeking from the user's perspective. Journal of the American Society for Information Science, Vol. 42 No. 5, pp361-371.

Kudielka, B. M., and Kirschbaum, C. (2005). Sex differences in HPA axis responses to stress: a review. Biological Psychology, 69(1), 113-132.

Kurbanoglu, S. and Buket, A. (2006). Developing the information literacy self-efficacy scale. Journal of Documentation, Vol 62 No. 6, pp.730-743. Available at: DOI: 10.1108/00220410610714949 (accessed 23 March 2019)

Kumar, S. and Edwards, M. E. (2013). Information literacy skills and embedded librarianship in an online graduate programme. Journal of Information Literacy, Vol. 7 No. 1, pp. 3-17. from http://ojs.lboro.ac.uk/ojs/index.php/JIL/article/view/PRA-V7-I1-2013-1 (accessed 23 July 2021) 
Lewandowsky, S. Ecker, U. K. H., Seifert, C. M., Schwarz, N., and Cook, J. (2012). Misinformation and its correction, continued influence and successful debiasing. Psychological Science in the Public Interest, Vol. 13 No. 3, pp. 106-131.

Lewandowsky, S. (2017). Beyond Misinformation: Understanding and Coping with the "Post-Truth" Era. Journal of Applied Research in Memory and Cognition, Vol.6, No. 4, pp. 353-369. https://www.sciencedirect.com/science/article/pii/S2211368117300700 (accessed 27 May 2020)

Lewandowsky, S. and Yesilada, M. (2021). Inoculating against the spread of Islamophobic and radical-Islamist disinformation. Lancaster: CREST. https://crestresearch.ac.uk/resources/inoculatingagainst-the-spread-of-islamophobic-and-radical-islamist-disinformation/ (accessed 23 July 2021)

Lloyd, A. (2010). Framing information literacy as information practice: site ontology and practice theory. Journal of Documentation, Vol.66, No. 2, pp.245-258.

https://doi.org/10.1108/00220411011023643 (accessed 23 July 2021)

Lloyd, A. (2016). Book and software reviews. Jacobson, Thomas P. and Mackey, Trudy E. (eds.) Metaliteracy in practice. London, UK: Facet Publishing, 2016. Information Research.

http://informationr.net/ir/reviews/revs567.html (accessed 23 July 2021)

Lloyd, A. (2017). Information literacy and literacies of information: a mid-range theory and model. Journal of Information Literacy, 11 (1), pp. 91-105. http://dx.doi.org/10.11645/11.1.2185 (accessed 23 July 2021)

Lloyd, A \& Williamson, K. (2008). Towards and understanding of Information literacy in context: Implications for research, Journal of Librarianship and Information Science, Vol. 40 No. 1., pp. 3-12 https://doi.org/10.1177/0961000607086616 (accessed 23 July 2021)

Mackey, T. P. (2020). Exploring Metaliterate learning through the frames of information literacy. In Julien, H., Gross, M. and Latham, D. The information literacy framework: case studies for successful implementation. London: Rowman \& Littlefield, pp. 206-218.

Mackey, T. P., and T. E. Jacobson. (2011) Reframing Information Literacy as a Metaliteracy. College and Research Libraries Vol. 72 No. 1, pp. 62-79.

Mackey, T. P. and T. E. Jacobson (Eds) (2014). Metaliteracy: Reinventing Information Literacy to Empower Learners. Chicago: ALA Neal-Schuman.

Mackey, T. P. and T. E. Jacobson (Eds) (2019). Metaliterate Learning for the Post-Truth World. Chicago: ALA Neal Schuman.

Marin, M. F., Morin-Major, J. K., Schramek, T. E., Beaupré, A., Perna, A., Juster, R. P., and Lupien, S. J. (2012). There is no news like bad news: women are more remembering and stress reactive after reading real negative news than men. PloS ONE, Vol. 7 No. 10, e47189.

Marzal, M. A. and Martinez-Cardama, S. (2020). Classification of academic research in metaliteracy. Spanish journal of Scientific Documentation, Vol. 43 No. 4, e279.

https://doi.org/10.3989/redc.2020.4.1728 (accessed 23 July 2021)

Meijen, C., Turner, M. J., Jones, M. V., Sheffield, D., and McCarthy, P. (2020). A theory of challenge and threat states in athletes: A revised conceptualisation. Frontiers in Psychology.

https://doi.org/10.3389/fpsyg.2020.00126 (accessed 23 July 2021)

Morgan, G. (2018). DCU leading major project to tackle 'fake news' spread on internet. Independent, 8th November 2018. https://www.independent.ie/irish-news/dcu-leading-major-project-to-tackle-fakenews-spread-on-internet-37505081.html (accessed 17 December 2018) 
Nicholas, D. (2000). Assessing information needs: tools, techniques and concepts for the Internet age. London: Aslib.

Nilus, S. (1905). The Jewish peril: the protocols of the learned elders of Zion. London: Eyre \& Spottswoode. (Facscimile published in 2009 by Martino Publishing Connecticut).

OfCom (2021). Understanding online false information in the UK. Economist Discussion Paper Series, Issue number 2. https://www.ofcom.org.uk/ data/assets/pdf file/0027/211986/understandingonline-false-information-uk.pdf (accessed 23 March 2021).

Office For National Statistics (ONS) (2021). Dataset: internet users. https://www.ons.gov.uk/businessindustryandtrade/itandinternetindustry/datasets/internetusers (accessed 23 July 2021)

Pickard, A. J., Shenton, A. K. and Johnson, A. (2014) Young people and the evaluation of information on the web: principles, practice and beliefs. Journal of Library and Information Science. Vol. 46 No. 1, pp. 3-20. Available at: DOI: 10.1177/0961000612467813 [accessed 30 November 2017]

Piccolo, L. S. G.; Joshi, S.; Karapanos, E. and Farrell, T. (2019). Challenging Misinformation: Exploring Limits and Approaches. In: Human-Computer Interaction - INTERACT 2019 (Lamas, David; Loizides, Fernando; Nacke, Lennart; Petrie, Helen; Winckler, Marco and Zaphiris, Panayiotis eds.), Lecture Notes in Computer Science, Springer, pp. 713-718.

http://oro.open.ac.uk/68822/3/Workshop_Misinformation_Interact.pdf (accessed 23 July 2021)

Ragonesi, A. J., and Antick, J. R. (2008). Physiological responses to violence reported in the news. Perceptual and Motor Skills, Vol. 107 No. 2, pp. 383-395.

Robson, C. and McCartan, K. (2016). Real world research (4th edn.). Hoboken: Wiley.

Ross, M. Perkins, H. and Bodey, K. (2016). Academic motivation and information literacy selfefficacy: The importance of a simple desire to know. Library and Information Science Research, Vol. 38 No. 11, pp. 2-9. https://doi.org/10.1016/j.lisr.2016.01.002 (accessed 23 March 2019)

Rubin, V. L. (2019). Disinformation and misinformation triangle: A conceptual model for "fake news" epidemic, causal factors and interventions. Journal of Documentation, 75(5), pp. 1013-1034. https:/www.emerald.com/insight/content/doi/10.1108/JD-12-2018-0209/full/html (accessed 23 July 2021)

Schatzki, T. R. (2000). The site of the social: a philosophical account of the constitution of social life and change. University Park, Pa: Penn State University Press.

Schlenger, W. E., Caddell, J. M., Ebert, L., Jordan, B. K., Rourke, K. M., Wilson, D. and Kulka, R. A. (2002). Psychological reactions to terrorist attacks: findings from the National Study of Americans' Reactions to September 11. JAMA, Vol. 288 No. 5, pp. 581-588. https://pubmed.ncbi.nlm.nih.gov/12150669/ (accessed 23 July 2021)

Schuster, M. A., Stein, B. D., Jaycox, L. H., Collins, R. L., Marshall, G. N., Elliott, M. N. and Berry, S. H. (2001). A national survey of stress reactions after the September 11, 2001, terrorist attacks. New England Journal of Medicine, Vol. 345 No. 20, pp. 1507-1512.

SCONUL (2013). The SCONUL 7 Pillars of information literacy through a digital lens. https://www.sconul.ac.uk/sites/default/files/documents/Digital_Lens.pdf (accessed 23 July 2021)

Secker, J. \& Coonan, E. (eds.) (2013). Rethinking information literacy: a practical framework for teaching. London: Facet.

Seery, M. D. (2011). Challenge or threat? Cardiovascular indexes of resilience and vulnerability to potential stress in humans. Neuroscience and Biobehavioral Reviews, Vol. 35 No. 7, pp. 1603-1610. 
Shenton, A. K. and Pickard, A. J. (2014a). Evaluating Online Information and Sources. Minibook Series: UK Literacy Agency.

Shenton, A. K. and Pickard, A. J. (2014b). Facilitating Pupil Thinking About Information Literacy. The New Review of Children's Literature and Librarianship. Vol. 20 No. 1, pp. 64-79. DOI 10.1080/13614541.2014.863671 (accessed 28 May 2020)

Shenton, A. K. and Pickard, A. J. (2012). The evaluation challenge. Creative Teaching and Learning. 13 (2), pp.22-28.

Siddiq, F. and Scherer, R. (2019). "Is there a gender gap? A meta-analysis of the gender differences in students' ICT literacy". Educational Research Review. Vol. 27 pp. 205-217.

https://doi.org/10.1016/j.edurev.2019.03.007 (accessed 28 May 2020).

Skinner, N., and Brewer, N. (2004). Adaptive approaches to competition: Challenge appraisals and positive emotion. Journal of Sport and Exercise Psychology, Vol. 26 No. 2, pp. 283-305.

Smith, M. (2011). Research methods in accounting (5th ed.). London: Sage Publications Ltd.

Spink, A., Wolfram, D., Jansen, B. and Saracevic, T. (2001). Searching the web: the public and their queries. Journal of the American Society of Information Science and Technology, Vol. 52 No. 3, pp.226-234.

Spring, M. (2020a). Coronavirus: The human cost of virus misinformation. BBC News, 27th May. https://www.bbc.co.uk/news/stories-52731624 (accessed 27tMay 2020).

Spring, M. (2020b). Stop the steal: The deep roots of Trump's 'voter fraud' strategy. BBC News, $23^{\text {rd }}$ November 2020. https://www.bbc.co.uk/news/blogs-trending-55009950 (accessed 23 July 2021)

Taber, C. S. and Lodge, M. (2006). Motivated skepticism in the evaluation of political beliefs. American Journal of Political Science, Vol. 50 No. 3, pp.755-769

https://onlinelibrary.wiley.com/doi/full/10.1111/j.1540-5907.2006.00214.x (accessed 28 May 2020).

Thompson, G.B. and Lathey, J.W. (2013). An integrated model of information literacy, based upon domain learning. Information Research, 18(3) paper C02. http://InformationR.net/ir/183/colis/paperC02.html (accessed 27 May 20202)

Trevors, G. J., Muis, K. R., Pekrun, R., Sinatra, G. M. and Muijselaar, M. M. L. (2017). Exploring the relations between epistemic beliefs, emotions, and learning from texts. Contemporary Educational Psychology, Vol. 48, pp. 116-132. http://dx.doi.org/10.1016/j.cedpsych.2016.10.001 (accessed 27 May 2020)

Turner, M. J., Jones, M. V., Sheffield, D. and Cross, S. L. (2012). Cardiovascular indices of challenge and threat states predict performance under stress in cognitive and motor tasks. International Journal of Psychophysiology, Vol. 86, pp. 48-57. doi:10.1016/j.ijpsycho.2012.08.004 (accessed 23 July 2021)

Veinberg, S. (2015). Digital native's attitude towards news sources. Public Relations Review, Vol. 41 No. 2, 299-301.

Vick, S. B., Seery, M. D., Blascovich, J. and Weisbuch, M. (2008). The effect of gender stereotype activation on challenge and threat motivational states. Journal of Experimental Social Psychology, Vol. 44 No. 3, 624-630.

Vosoughi, S. Roy, D. and Aral, S. (2018). The spread of true and false news online. Science, 359, (6380), pp.1146-1151. DOI:10.1126/science.aap9559 (accessed 23 July 2021)

Walton, G. (2017). Information literacy is a subversive activity: developing a research-based theory of information discernment. Journal of Information Literacy, Vol. 11 No. 1, 137-155.

http://dx.doi.org/10.11645/11.1.2188 (accessed 27 May 2020) 
Walton, G. and Hepworth, M. (2011). A longitudinal study of changes in learners' cognitive states during and following an information literacy teaching intervention. Journal of Documentation. Vol. 67 No. 3, pp. 449-479.

Walton, G. and Hepworth, M. (2013). Using assignment data to analyse a blended information literacy intervention: A quantitative approach. Journal of Librarianship and Information Science, Vol. 45 No. 1, pp. 53-63.

Walton, G. and Cleland, J. (2017). Information literacy - empowerment or reproduction in practice? A discourse analysis approach, Journal of Documentation, Vol. 73 No. 4, 582-594.

https://doi.org/10.1108/JD-04-2015-0048 (accessed 27 May 2020)

Walton, G., Pickard, A. and Dodd, L. (2018). Information discernment, misinformation and pro-active scepticism, Journal of Librarianship and Information Science, Vol. 50 No. 3, pp.296-309. http://journals.sagepub.com/doi/abs/10.1177/0961000618769980 (accessed 27 May 2020)

Watson, D., Clark, L. A. and Tellegen, A. (1988). Development and validation of brief measures of positive and negative affect: the PANAS scales. Journal of Personality and Social Psychology, Vol. 54 No. 6, pp. 1063 - 1070

Whitworth, A. (2020a). The discourses of power, information and literacy. In In Goldstein, S. (ed). Informed societies - why information literacy matters for citizenship, participation and democracy. London: Facet, pp.25-46.

Whitworth, A. (2020b). Mapping information landscapes: new methods for exploring the development and teaching of information literacy. London: Facet.

Wilson, T. D. (1999). Models in information behaviour research. Journal of Documentation, Vol. 55 No. 3, pp. 249-270.

Wong, K., Walton, G. and Bailey, G. (2021). Using information science to enhance educational preventing violent extremism programs. Journal of the American Society of Information Science \& Technology, Vol. 72 No. 3, pp. 362-376. http://dx.doi.org/10.1002/asi.24408 (accessed 24 March 2021)

Zaracostas, J. (2020). How to fight an infodemic: WHO's newly launched platform aims to combat misinformation around COVID-19. The Lancet, Vol. 395, p. 676.

https://www.thelancet.com/journals/lancet/article/PIIS0140-6736(20)30461-X/fulltext (accessed 27tMay 2020)

Zimmerman, B. J. (2000). Self-efficacy: An essential motive to learn. Contemporary Educational Psychology, Vol. 25 No. 1, pp. 82-91. https://doi.org/10.1006/ceps.1999.1016 (accessed 27 May 2020)

Zyoud, S.H., Sweileh, W.M., Awang, R. et al. (2018). Global trends in research related to social media in psychology: mapping and bibliometric analysis. International Journal of Mental Health Systems, 12, 4. https://doi.org/10.1186/s13033-018-0182-6 
FIGURE 1: Information Discernment Framework (Walton 2017, p139 adapted from Walton and Hepworth's information literacy behaviour model, 2011, p470 itself based upon Hepworth, 2004, p.705)
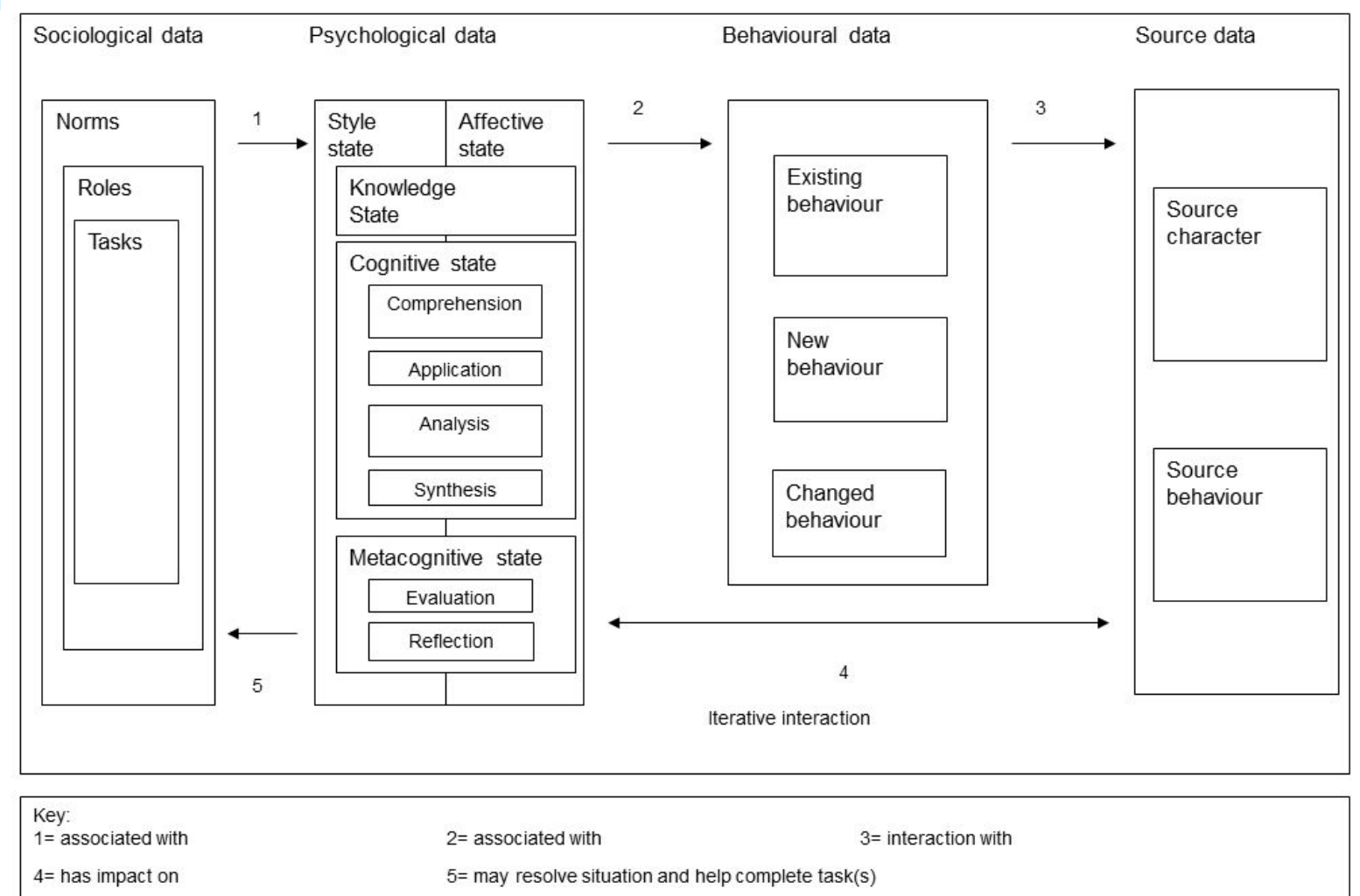
FIGURE 2: 'Articulation' of the knowledge state (Walton 2017, p150)

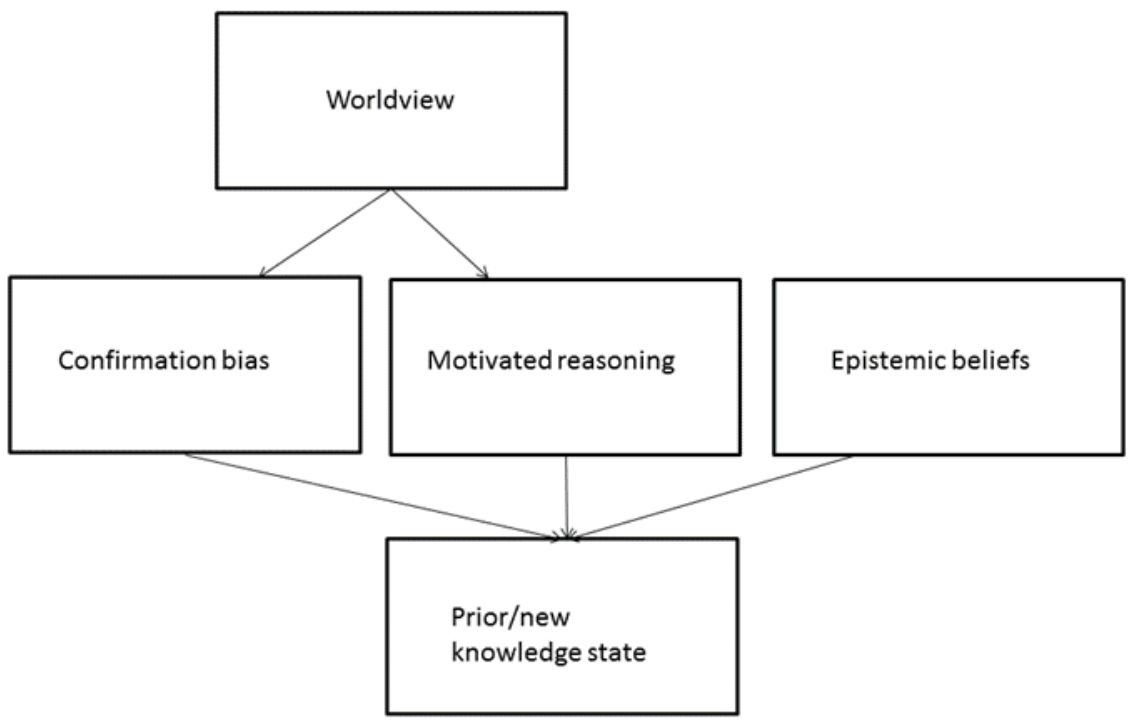


FIGURE 3: Experimental protocol

Participants sent and completed pre-screening questionnaire which included demographic questions and the religiosity scale and provided with date/time to arrive at the lab.

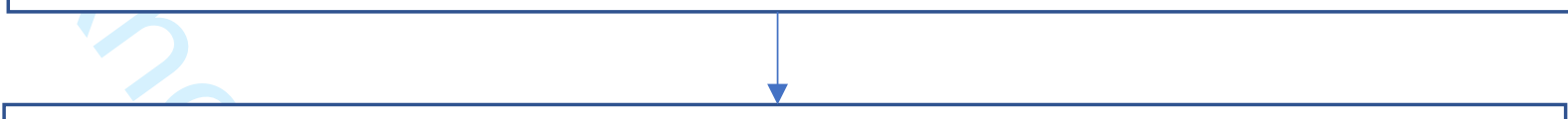

Participant and confederate arrived at the lab and 'randomly' allocated to different labs. The participant always remained within the first lab, but 'random' allocation was conducted to maintain deception.

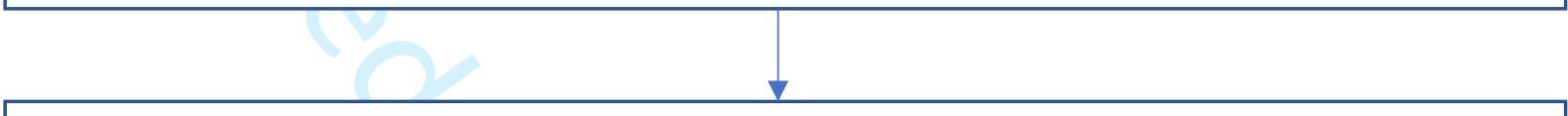

Once confederate had left, participants completed self-efficacy questionnaire and informed consent and were connected to the Finometer Pro. Participants read 6 news articles with religious themes. Pressure-inducing instructions were then provided to induce a stress response, with a further 2minutes of $\mathrm{CV}$ measures to capture changes from baseline. Participants completed pre-task questionnaires here also.

Pressure instructions informed participants that they would be completing a word-search task that their fellow participant (confederate) had just attempted. Should they complete the task within 3-minutes they would win the fellow participant $\mathrm{f100}$. Pre-screening data regarding the confederate was shared with the participant, including demographic data. $50 \%$ of participants were also provided with the confederates religiosity scores, falsely stigmatizing participants to believe the confederate was a religious extremist.

The task would be ended after 3-minutes or when every word had been found. To ensure participants were engaged and motivated throughout the 3-minutes though, participants were never told if they had completed the task. Post-task questionnaires were then completed. A full debrief was provided to participants with all deception revealed. 
Table I: Means and S.D. of key variables for stigmatized group

\begin{tabular}{lllll}
\hline & \multicolumn{2}{l}{ Low ID (N=14) } & \multicolumn{2}{l}{ High ID (N=10) } \\
\cline { 2 - 5 } & Mean & SD & Mean & SD \\
\hline Self-efficacy & 67.70 & 9.27 & 73.88 & 11.64 \\
Pre-positive emotion & 2.64 & .54 & 3.25 & .75 \\
Post-positive emotion* & 2.78 & .77 & 3.52 & .44 \\
Pre-negative emotion & 1.24 & .29 & 1.36 & .54 \\
Post-negative emotion & 1.35 & .32 & 1.51 & .54 \\
Pre-demand and resource appraisal & 0.93 & 1.14 & 1.60 & 1.43 \\
Post-demand and resource & -0.43 & 1.16 & 0.80 & 1.55 \\
appraisal* & & & & \\
CO reactivity & 0.14 & .58 & 0.50 & .46 \\
TPR reactivity & 19.85 & 76.98 & 0.63 & 46.54 \\
CTI & -0.70 & 2.13 & 0.46 & 1.28 \\
\hline
\end{tabular}

*Significant interaction effects 
Appendix 1 - Experimental protocol - additional detail

A Finometer Pro (Finapres Medical Systems, Enschede, The Netherlands) was used to collect CV data from participants. A finger-cuff attached to the participant's middle finger upon the non-dominant hand constantly measured changes in arterial pressure. Three key CV measures can be collected from these measures; Heart rate (HR), Cardiac Output (CO), and Total-Peripheral Resistance (TPR). A significant increase of HR denotes SAM activity indicating task engagement and provides evidence as to whether stress manipulation has been successful. Measures of CO and TPR are then used as indices of challenge and threat. By converting both $\mathrm{CO}$ and TPR reactivity measures into z-scores and summing them, as in the majority of challenge and threat research (e.g., Turner et al., 2013), a single Challenge and Threat Index (CTI) was also created. The CTI can be positive or negative, and a positive $\mathrm{CTI}$ represents a challenge $\mathrm{CV}$ response, whilst a negative $\mathrm{CTI}$ score represents a threat $\mathrm{CV}$ response.

\section{Challenge and Threat Psychometrics}

Certain psychometric measures were also collected to complement the challenge and threat $\mathrm{CV}$ responses. Participants were asked to indicate on a Likert scale ranging from 1 (not at all) to 6 (extremely) how demanding they thought the task would be and how likely it was that they would be able to cope with these demands. These two questions provide an assessment of challenge and threat self-reported appraisals. Furthermore, participants were asked to answer how motivated they felt to perform the task well, how motivated they were to help the other participant, and how much effort they would put into the task, all of which were rated on a Likert scale ranging from 1 (none) to 6 (maximum). These measures complemented HR data in ascertaining whether the task was motivationally relevant for participants. Finally, the Positive Affect Negative Affect Survey (PANAS; Watson et al., 1988) was used to assess affective responses of participants before completing the task. The PANAS consists of 10 items measuring negative affect, and 10 items measuring positive affect, all of which are answered on a scale ranging from 1 (not at all) to 5 (extremely).

\section{Procedure}

Initially, participants were sent a pre-screening questionnaire containing a participant information sheet, the religiosity scale, and the information discernment questionnaire. Once completed, participants were provided with a date and time to visit the lab to complete the study.

The participant entered the lab along with the confederate, with both welcomed in the same manner to reduce suspicions of a researcher-confederate relationship. Both the confederate and participant were informed that the experiment would be taking place across two labs, and that they would randomly draw from an envelope to decide which lab they would be tested in. However, this draw was controlled for to ensure the participant remained within the lab and that the confederate could leave. The participant was then led to believe that the confederate was being escorted to the other lab. Participants now completed the self-efficacy measure and informed consent whilst waiting for the researcher to return.

Once the researcher had returned, participants were connected to the Finometer Pro and eyetracking equipment were calibrated. Participants were asked to read 6 religious themed news articles whilst eye-tracking and CV data were collected. Once finished, participants were instructed to sit quietly for 10-minutes whilst baseline CV measures were accumulated. This baseline period is essential to ascertain changes in $\mathrm{CV}$ responses from rest to the introduction of pressurised instructions and is common throughout the challenge and threat literature (Behnke and Kaczmarek, 2018).

Upon completion of baseline CV measures, participants were blindly and randomly provided with task instructions and asked to read these allowed to ensure engagement. All instructions informed participants that they would be attempting to complete a word search task for their fellow participant (our confederate). Participants were told that the confederate had already attempted 
the word search in the other lab but had failed to finish, therefore should they manage to complete the word search they would win the confederate $f 100$. Participants were then provided with some fabricated demographic information about the confederate (e.g., name and age). However, half of participants $(n=24)$ were informed that the confederate had scored highly upon the religiosity scale that had been completed during the pre-screening process. This misinformation (in addition to the 6 negative religious themed articles) was aimed to influence participants to believe the confederate was highly religious (high-stigma condition).

Following the reading of task instructions participants sat still for a further 2-minutes so that CV responses could be captured and completed post-instruction questionnaires based upon how they felt regarding the word search task (e.g., PANAS, demand/resource appraisals, motivation/effort). Eye-tracking equipment was again calibrated and used whilst participants completed the task. Following 3-minutes of task performance participants completed a similar battery of questionnaires as to those completed prior to the task, had all equipment removed, and were fully debriefed concerning all manipulations and the actual aims of the study. Prior to the debrief, participants were asked for their thoughts about the study to further check manipulation success. 